\title{
EMPIRICISM, TIME-AWARENESS, AND HUME'S MANNERS OF DISPOSITION
}

\author{
ADRIAN BARDON \\ Wake Forest University
}

\begin{abstract}
The issue of time-awareness presents a critical challenge for empiricism: if temporal properties are not directly perceived, how do we become aware of them? A unique empiricist account of time-awareness suggested by Hume's comments on time in the Treatise avoids the problems characteristic of other empiricist accounts. Hume's theory, however, has some counter-intuitive consequences. The failure of empiricists to come up with a defensible theory of time-awareness lends prima facie support to a non-empiricist theory of ideas.
\end{abstract}

\section{INTRODUCTION}

St. Augustine's central theses about time - namely, that the past and future do not exist and that the present does not have duration - imply that temporal properties like duration, succession, and time-order are not directly perceived. Augustine puzzles over how he can assess the length of time taken up by a movement or a noise, if he has no direct perceptual awareness of any part of the process other than that occurring at the present moment (Augustine, Confessions, 1961, 11.26-8). He replies that he can retain the idea of a process of particular duration, and use it as a "standard of measurement." But he notes that it cannot literally be the process that is the standard of measurement, since it is no longer present. Instead one measures duration by reference to a represented benchmark fixed in one's memory. A notion of the passage of time is achieved by recollecting past mental contents and comparing them to present ones. The parts of the mental representation of a duration stand for elapsed parts of a process being measured.

This story takes one important fact for granted. My mental states could only serve to represent duration in this way if I already have the concept of duration, or

The Journal of Scottish Philosophy, 5 (1) 2007, 47-63

ISSN 1479-6651 
at least some other temporal concept like succession from which the idea of duration could be derived. No mental representation has temporal content in itself; if Augustine is right in saying that only the present moment is directly perceived, then his mental affections are just states with the mere potential to be employed as stand-ins for duration and passage. If we do not have a direct awareness of anything outside the present moment, and we are not to conclude that our idea of time is a priori, then we must come up with an account of the experiential origin of temporal concepts like duration and succession. C.K. Mundle describes the problem for the empiricist who accepts Augustine's two theses about time:

[W] hatever relations may hold between the images (or between the images and the sensa or percepts) which a person has at any durationless instant, the relation of temporal precedence cannot be among them, for this relation holds, by definition, between items which are not simultaneous. The would-be empiricist would thus have debarred himself from saying what he wants and needs to say, i.e., that our temporal concepts are constructed from (can be defined in terms of) temporal relations like earlier than which are sense-given (can be ostensively identified). (Mundle, 1966, p. 166) ${ }^{1}$

The empiricist, characteristically, maintains the truth of the principle that all simple ideas must be derived from original sense-impressions, or from impressions of reflection upon the mind's own contents or operations (the 'copy principle'). ${ }^{2}$ (Treatise 1.1 .1 ; 4) All complex ideas are derived from sensation, from a combination of simple ideas, or from reflection. Hence the problem of time for empiricism: how are concepts like duration or succession derived from sensation or reflection? This problem was taken up by empiricists such as Locke, James, Russell, and Broad (as discussed in Mundle, 1966). Locke's failure to give a satisfactory account of how these concepts could be derived from sense-experience is instructive. He holds that we have a direct, reflective perception of the succession of our ideas: we gain the idea of succession simply by reflecting on the train of ideas as it passes through our mind (Locke, 1975, p. 182). The idea of duration, in turn, is just the idea of the distance (measured by number of elapsed ideas) between any two of our ideas.

This account is not satisfactory. In order actually to have a direct perception of a succession, I would have to perceive, all at once, a temporally-extended series. But for Locke, our ideas come to us, as it were, one by one. At any given moment, I have only one idea before me (or, perhaps, several simultaneous ones). The succession of my ideas is never truly before me at a time. (This is pointed out by Sean Kelly (Kelly, unpublished)). Even if I simultaneously recollect past ideas, and reflect on them together with my present idea(s), the content of my current mental state is not that of a succession; it is that of a set of ideas held simultaneously, some of which happen to be products of mental reproduction, and some of which happen to be products of present perception. In his account of memory, 
Locke just describes the mind's power to reproduce perceptions together with a perception that one "has had them before" (Locke, p. 150). But the origin of this sense of 'beforeness' is a mystery. I could interpret some of my currently-held ideas as reproductions, and thus the whole set as a succession, but only if I already had a sense of what it is for something to be a reproduction. Without an idea of time already in play, there can be no awareness of succession among a set of ideas reflected upon at a time.

Locke's failure to explain time-concepts, and the resulting perceived inability of empiricists to account for time-concepts, is extremely important because this inability is the foundation of Kant's argument for the role of a priori concepts in cognition and the consequent possibility of synthetic a priori knowledge. In his Critique of Pure Reason, Kant argues that time is best understood as a form of experience: we are constructed so as to experience events and our own mental states successively. However, as Kant intimates, successions of perceptions and enduring perceptions are not by themselves, respectively, representations of succession or duration (Kant, 1998, pp. 228-9 and 300 (A99 and B225)). He argues that awareness of a succession as such requires the formal concept of an objective world, spelled out in terms of time and space. Thus the elements making up this concept of an objective world - including, he argues, the concepts of substance and cause - must be a priori. Since coherent experience requires that we organize experience according to such concepts, we can say that we are entitled to apply them to experience. This is the essence of Kant's answer to empiricist skepticism.

In defense of an empiricist theory of time-awareness, Bertrand Russell maintained that, at any given moment, what we directly experience is a stretch of time. Russell's view was that a sense-organ, when stimulated, "goes on vibrating, like a piano string" for a while after the stimulation (Russell, 1927, p. 205). In the period during which the sensation fades, we literally perceive now what happened a short while ago. It is because of this effect that we see, for example, the movement of a second-hand: we can see a second-hand moving because we literally see it, at one moment, in several places.

H.J. Paton argued in response that, even if it were true that we could sense at a moment several different positions of the second-hand of a watch, the simultaneous perception of these positions would not be a perception of movement but of something else:

if in a moment I can sense several different positions of a second hand, then these different positions would be sensed as being all at the same moment. That is to say what I should sense would not be a movement, but a stationary fan covering a certain area, and perhaps getting gradually brighter towards one end. Anything else would surely be a miracle. You can't see a sensum that isn't there. If you see it, it is there at the time you see it. (Paton, 1929, p. 320) ${ }^{3}$

Experiencing the temporally-diverse parts of a temporally-extended process all 
at once does not count as having a direct experience of a process any more than experiencing a current part of a process while recollecting past components of the process. (See Mundle, 1966. This point is also discussed in Kelly, unpublished.)

C.D. Broad responded to this criticism by arguing that there is an aspect of how mental contents are intended he called "presentedness" (Broad, 1938, p. 282. Cf. also Odegard, 1978, p. 117). The later parts of a perceived duration, he claimed, have a greater degree of this quality. This is what gives us the experience of motion as opposed to a "stationary fan." Douglas Odegard replies that, if this just means that the later parts of the process are presented more vividly than the earlier parts, then nothing is communicated about the temporal status of the perceived parts (Odegard, p. 117). Perhaps for this reason Broad conceded that the introduction of the presentedness quality appears to be a "verbal trick" for dealing with Paton's objection (Broad, p. 282).

According to the Augustinian presumptions, we only know the past by virtue of something standing in for it now, and anything standing in for what happened in the past needs to be interpreted as communicating temporal information (Cf. Guyer, 1987, pp. 302-3). But whether what is being so interpreted is a mental representation of elapsed duration, a recollected idea, a sensation that is the result of reverberating sense-organs, or a degree of presentedness, an interpretation in terms of time is required. And no such interpretation can take place without the application of temporal concepts.

Mundle's answer involves rejecting the Augustinian problem for time-awareness. He agrees that Paton's criticism of Russell is valid. However, he thinks the empiricist has no genuine problem with time-awareness stemming from that puzzle because one of Augustine's theses is false: namely, that the present of observation has no duration. He points out that most would agree that "sensa" (individual sensation-events) have duration: because infinitesimal periods of sensory input cannot be sensed, events of observation take time to occur. Thus the length of time taken up by a perceptual event is not infinitesimal, but rather incorporates a period of sensory input that itself can include a change in content. The present of perception, then, is an extended period of time. It follows, he claims, that we can say that we can experience succession in one perceptual act, and so we sense temporal relations:

If we use sensum-language, we are free to adopt rules which will allow empiricists to say what they need to say, i.e., that temporal relations (precedence, overlapping, etc.) hold between different sensa and between different states of the same sensa, that these relations are sense-given. (Mundle, p. 168)

Mundle must be defining the 'present' of perception as the span of time coextensive with a temporally-extended sensation-event. Otherwise, we would have another 'Paton miracle' on our hands: namely, the direct, present sensation of past events. Because he thinks that perceptions are themselves temporally extended, he 
also thinks we can embrace, in one perceptual act, a change in sensation.

Extended, single acts of awareness are what proponents of a "specious present" of perception have suggested, some even citing, in an attempt to establish the length of the specious present, empirical studies concerning the span of time with a length that is accurately estimable, or that is accessible to short-term memory without error (Mabbott, 1967). Spatial perception can encompass more than one minimum in one momentary act of awareness; why not temporal perception in one extended act? But, as J.D. Mabbott has pointed out, if both acts of awareness and their objects were extended in time, it would be impossible to assign contents to those acts of awareness (Mabbott, pp. 310-11). For any event-span supposedly directly 'given' over the course of an extended act of awareness, part of what is thereby directly given to part of the act will not be given to another part. But then there is no event the act of awareness could apprehend as a whole. Mabbott concludes that "the doctrine of the specious present is untenable and sheds no light on our normal apprehension of temporal events."

\section{HUME ON THE ORIGIN OF TEMPORAL CONCEPTS}

To the extent that they accepted Augustine's premises, each of the later defenders of empiricism faced a seemingly insurmountable conundrum in trying to account for temporal concepts: on the one hand, we need to form temporal concepts from materials we have at hand at a given moment; on the other, to think of such materials as representing duration or succession it seems we must deploy temporal concepts (cf. Kelly, forthcoming) So where do these concepts come from? Hume's fundamentally different approach to the problem has received relatively little attention, yet, interestingly, suggests an account of time-awareness that avoids the circularity problem to which many empiricist accounts are subject. It bears closer examination for this reason, though in the end there are serious concerns as to its coherence and plausibility.

In his Treatise of Human Nature Hume rejects the infinite divisibility of space and time, and argues that the ideas of empty space and empty time are incoherent. He proposes that impressions of spaces and times are composed of indivisible parts he calls perceptual "minima," and that ideas of spaces and times are composed of corresponding ideas. He defines perceptual minima as the minimum perceivable qualitative units of sense-experience. An example he gives is the simple idea of color generated by the perception of a spot of ink at the limit of its perceivability (Treatise 1975, 1.2.1; 27). The spot of ink any farther away would be imperceptible. Any closer and the impression of it would be divisible into smaller impressions. For him, then, the impression and the corresponding idea of the spot are simple, with color but no divisible extension.

Hume's next task is to ask from whence the idea of time derives, given his view 
that all simple ideas derive from simple impressions of sensation or reflection, and any complex ideas must be traceable to these. His account of the origin of the idea of temporal succession runs as follows:

The idea of time is not deriv'd from a particular impression mix'd up with others, and plainly distinguishable from them; but arises altogether from the manner, in which impressions appear to the mind, without making one of the number. Five notes play'd on a flute give us the impression and idea of time; tho' time be not a sixth impression, which presents itself to the hearing or any other of the senses. Nor is it a sixth impression, which the mind by reflection finds in itself. ... [H]ere [the mind] only takes notice of the manner, in which the different sounds make their appearance; and that it may afterwards consider without considering these particular sounds, but may conjoin it with any other objects. (Treatise, 1.2.3; 36-7)

We have no distinct sensory impression of time in itself. Since the minimal units of sensation are themselves indivisible and momentary, duration is not a qualitative aspect of sensation (Treatise 1.2.3; 37) (See Falkenstein, 1997, p. 184). In fact, no notion of times independent of changing perceptions or events is even conceivable, according to Hume: the idea of an extended period of time is derived from the experience of a succession of impressions, and has no application in the absence of any succession. ${ }^{4}$

Neither is the idea of time derived from impressions of reflection, in that there are no single impressions of reflection of which ideas of times are ideas. Hume does say elsewhere that memories are distinguished from products of imagination by their force and vivacity, and that newer memories tend to be "clearer" than older ones (Treatise, 1.3.5; 85). But this is never put forward as a rule (see Falkenstein, 1997 p. 186). And this vivacity, or clarity, itself is not the impression of time. ${ }^{5}$

So what explains our idea of time? For Hume, our ideas of particular time-intervals come first. Our ideas of times are said by Hume to derive not from a separate impression of the duration of an event, but from the very disposition, the very manner of the appearance, of the successive momentary impressions making up the compound impression of the event. ${ }^{6}$ On Hume's view our experience primordially consists of collections of simple impressions. But any collection of simple impressions must be a collection of "simple impressions disposed in a certain manner" (Falkenstein, 1997, pp. 188-9). The manner of disposition of the parts of our experience in time, as Hume stresses, is an aspect of all our experience, both sensory and reflective (Treatise, 1.2.3; 34-5) As Lorne Falkenstein has recently pointed out, many interpreters of Hume have rebelled against this proposal, because it seems to violate the dictum that the contents of all ideas are traceable to original simple impressions (Falkenstein, pp. 180-1). For this reason some Hume scholars, including Robert Fogelin and B.M. Laing, have sought to interpret the Treatise in such a way that Hume is found to derive the ideas of space and time 
from impressions thereof (Cf. Falkenstein, pp. 183-5). But Falkenstein replies that the manners of disposition of our impressions are present in compound impressions, and it is not a violation of empiricist principles to allow ideas copying these manners of disposition (Falkenstein, p. 182; see also Garrett, 1997, pp. 52-7). For Hume, "our ideas of particular (bounded and sensibly qualified) spatiotemporal intervals are direct copies, not just of simple impressions, but of simple impressions disposed in a certain manner" (Falkenstein, p. 182). Ideas of manners of disposition, then, do not go beyond what is "directly and immediately given in sensory experience," even though they do go beyond what is directly given in any particular simple impression (Ibid. p. 190). ${ }^{7}$

On this account, the ideas of space and time in general (as opposed to particular space- and time-intervals) are abstract ideas, arrived at by "distinction of reason." (See Tweyman, 1974; also Garrett 1997, for a good exposition of Hume's theory of abstract ideas.) On the above reading, we gain ideas of particular extensions and durations simply by experiencing the manner in which our simple impressions are arrayed in space and time; by focusing, through a distinction of reason, on the feature of these manners of disposition that they have in common, the mind is spurred by the respect in which they resemble each other to take a particular idea and treat it as representative of a class. ${ }^{8}$ The problem of time-awareness under consideration concerns the origin of ideas of succession and duration in experience. Since abstract ideas, for Hume, are really ideas of particulars, the main issue in explaining the origin of the idea of time becomes the origin of ideas of particular times. His answer is that ideas of particular temporal intervals derive from the experience of manners of successive disposition of impressions. He describes the idea of time without a changeable object, just like the idea of empty space, as a "fiction," that we only "fancy we have" (Treatise, 1.2.3; 37, T 1.2.5; 65). But this is by contrast to the idea of time derived from an experience of a succession. This contrast shows he took the idea of a temporal interval to be a real idea.

The challenges for this Humean view can be best understood in the context of a criticism by M.R. Annand (as discussed by Falkenstein, 1997, pp. 193-6). Annand made the Kantian charge that Hume cannot account for how we get from a succession of perceptions to a representation of succession (Annand, 1930). This is the same problem, essentially, as the one faced by the other defenders of empiricism: the mere fact that a change in perceptions has taken place does not seem to amount to the experience of a change without a further temporal interpretation of one's present mental contents.

The solution suggested by Hume's comments is to collapse the distinction between a succession of perceptions and a representation of succession, by combining his point about copying manners of disposition with a principle according to which ideas represent by duplicating the qualities of their object.

Hume describes ideas as "images" and "copies" of impressions and outer objects, and states that ideas "resemble" those things they represent. (Cf. Treatise 
1.1.1; 1, T 1.2.5; 63, T 1.3.1; 72, T 1.4.5; 232-3. See Anderson, 1976, p. 163.) Following Robert Anderson (Anderson, 1976), Falkenstein argues that Hume has a theory of mental representation stating that our perceptions of outer things are mental objects representing those outer things via qualitative resemblance. A literal interpretation of the copy principle suggests that, for an idea to represent either an impression or a real object, the idea must resemble that which is represented. "[H]ow can an impression represent a substance," Hume asks, "otherwise than by resembling it?" (Treatise 1.4.5; 233). This Falkenstein terms the "likeness principle" (Falkenstein, 1995, p. 28). Hume's view, he says, is that perception "supplies us with a direct acquaintance with 'reflective images' that represent external objects to us in the way the image of a mountain reflected in a lake represents the mountain ... the way these images represent external objects is by a literal picturing that involves a quality-for-quality correspondence" (Falkenstein, 2002, p. 29). Thus impressions and ideas represent their object literally by copying them - by duplicating their qualities:

When Hume's own account of what it means for an idea to represent an object is taken into account, the distinction between an ordered series of perceptions and the perception of an ordered series collapses ... Hume does not take an idea to be an act whereby a mind thinks of or intends a particular object (in this case, a relation of adjacency in space or succession in time). Instead, he takes ideas to be objects in their own right, that represent something else by resembling it. An idea of space represents space by being itself extended in space, not by being 'of' space; an idea of time represents time by enduring over time. ... [T]o have an idea of succession is to have an idea that takes time to occur, and over which a number of parts occur successively. ... Annand's distinction between a succession of perceptions and a perception of succession is therefore one that Hume would reject. Ultimately, our 'perceptions of succession' just are ideas that represent the fact of succession by containing two parts, one of which is represented prior to the other over the time that the idea takes to occur. In other words, our perceptions of succession are ultimately no more than successions of ideas. (Falkenstein, 1997, pp. 193-5)

In support of this interpretation, Falkenstein cites Hume's description of a perception having parts that are arranged in space:

That table, which just now appears to me, is only a perception, and all its qualities are qualities of a perception. Now the most obvious of all its qualities is extension. The perception consists of parts. These parts are so situated, as to afford us the notion of distance and contiguity; of length, breadth, and thickness. ... And to cut short all disputes, the very idea of extension is copy'd from nothing but an impression, and consequently must perfectly agree to it. To say the idea of extension agrees to any thing, is to say it is extended. (Treatise 1.4.5; 239-40, emphasis added) 
There are a number of passages in the Treatise where Hume says that ideas are extended in space and have location. He describes ideas as extended in the brain, and he insists that some ideas can be relatively large or small (Treatise, 2.2.8; 372, T 1.2.1; 28). (See Anderson, 1980.) He also explains that the mind excites ideas when it "dispatches the spirits into that region of the brain, in which the idea is placed" (Treatise 1.2.5; 60-1). ${ }^{9}$

According to this reading, Hume does not need to explain how to represent a succession of perceptions as a succession: owing to his application of the likeness principle to manners of disposition, whenever one undergoes any succession of perceptions, one ipso facto has a representation of succession. Hume avoids the Augustinian problem by showing that our awareness of time does not happen at a moment and originate in the interpretation of recollected content or reverberations, but rather is an extended sequence of impressions. For Augustine and Locke, by contrast, the past can be an object of thought only by virtue of memory. Russell and Broad tried to solve the problem by claiming that we are able directly to sense the past at the present moment, but they were not able to account for the perception of motion or change. The Humean theory that ideas of successions are copies of the temporal arrangement of the parts of successions of impressions treats all parts of a succession - past and present - equally as contributing to an idea of the succession. Parts of the idea are distinguished from each other as being earlier and later, but are not distinguished from each other as being products of memory vs. products of current perception. ${ }^{10}$ Unlike Mundle, however, Hume's proposal under the likeness principle is that the awareness of a succession is fundamentally composed of a series of awarenesses appropriately related to each other, rather than a single, temporally-extended awareness. Thus Mabbott's concern that the parts of a single, temporally-extended awareness cannot share an object of awareness does not apply.

\section{AWARENESS OF SUCCESSIVE PARTS AND AWARENESS OF SUCCESSION}

There are, however, troubling questions to be considered with regard to the Humean theory described above. First, there is Hume's inherent rejection of Augustine's 'presentism'. Hume's account implies we cannot discount our access to previous parts of an experience of a succession as any less accessible (i.e., accessible merely to recollection) than the present moment. This seems problematic owing to the intuitive difficulty posed by the notion of the past (or future) existing just as the present does, which would seem to be a prerequisite for succession being a possible object of direct awareness. There is an extensive literature on "presentism" (the doctrine, embraced by Augustine, that only the present exists) and its opponents, which is much too vast to be dealt with here. ${ }^{11}$ However, in addition to the other questions raised above against the Humean approach to timeawareness, a defender of that approach must show that the position that past events 
exist in just the same way as present ones do is acceptable, despite (admittedly debatable) commonsense intuitions to the contrary. Otherwise, we cannot identify each act of awareness over a stretch of time as real. Unless the past exists, part of that overall experience will no longer be real; and if awareness is actual only now, then the sense in which an awareness of the past persists must make reference to retention, rather than to direct awareness. Further, it is one thing to say the past exists and another to say that we can have direct awareness of it. Even if we reject Augustine's presentism, the defender of the Humean approach under consideration must offer a coherent view according to which a whole succession can be an object of direct awareness.

My second point has to do with identifying the time of the idea of succession. Keep in mind that we are not talking about the reconstruction of a succession after the fact. Hume is accounting for the experience - the generation of the idea of - a succession or process as it occurs. He claims we glean the idea of a succession from a sequence of perceptions - that there is no distinction between a succession of perceptions and a perception of succession. Recall that he reifies experience by temporal minima; but take any experienced succession of temporal perceptual minima, located, respectively, at moments $\mathrm{t}_{1}-\mathrm{t}_{\mathrm{n}}$ : the account under consideration implies that there is a series of experiences taking place from $t_{1}-t_{n}$ (distinguishable by the minima they are experiences of), and a single experience, the direct object of which is the entire succession. So what am I observing now, at the present moment (say, at some moment $t_{m}$, between $t_{1}$ and $t_{n}$ ) - the minimal impression or event that is happening now, or an entire extended succession of impressions or events? The notion of such a consciousness implies that there is no answer to the question, when one is in the grips of such an experience, as to what idea one has at any given moment. There is the component-perception of the moment, but the experience or idea that is the object of this consciousness 'belongs' to the entire extended time of the experience, and is not ascribable to the subject of the experience at any particular time. Can the notion of an observation-event have any meaning if we are not talking about what is observed at a time? ${ }^{12}$ Take time $t_{\mathrm{m}}$ as described above, and call the idea of the manner of disposition of the experiences at $\mathrm{t}_{1}-\mathrm{t}_{\mathrm{n}}$ idea $\Omega$. At $\mathrm{t}_{\mathrm{m}} \mathrm{I}$ exist (or, as Hume might put it, a bundle of ideas $\beta$ exists), and I have some ideas at $\mathrm{t}_{\mathrm{m}}$ and don't have others (or some ideas belong to $\beta$ at $\mathrm{t}_{\mathrm{m}}$ and some don't). Do I have $\Omega$ at $\mathrm{t}_{\mathrm{m}}$ or don't I? (Does $\Omega$ belong to $\beta$ at $\mathrm{t}_{\mathrm{m}}$ or doesn't it?) It seems that there should be a definite answer to this question, but on the account of experience under consideration there is none.

There are many ways one could define the "present" in the context of "present experience" (Lacey, 1968, pp. 241-2). Augustine himself notes that we can perfectly well talk about the "present" day, month, or century, but adds that this convention does not imply anything about the reality of the past or future (Confessions 11:15). It is possible, of course, to say one is currently enjoying a symphony, but this does not mean that one is at this time exposed to more than the notes being played right 
about now; there are penumbral uses of the term 'experience' that allow extended objects of observation, just as there are uses of the term "present" that encompass extended units of time. Hume argues against the infinite divisibility of time, but his temporal minima by definition do not encompass changes in perceptual content. To think in terms of extended experience is to say that one has the experience of a succession over the whole time during which the succession occurs, but not at any point during that period. It seems the only way to allow for extended experience like this is to abandon the notion of a 'now' of experience. But by dividing all experience into distinguishable minimal perceptions lacking divisible extension in time, Hume has seemingly answered the question of what constitutes the present. One would think the answer to what one is experiencing now, or what ideas one has now, could naturally be answered by reference to those. ${ }^{13}$

Consider also the related issue of circumscribing observation-events. If any extended experience of any succession counted as a single experience of that succession, one's experience of the manner of disposition of a set of event-parts would count as a direct observation, even if the impressions of some of those event-parts took place hours ago. Certainly one may have directly observed the hour-old parts of an hour-long sequence an hour ago, and subsequently the rest of it as well. So in that sense one can execute an hour-long direct observation of an hour-long sequence. But on the Humean account this 'extended' observation would really be constituted by a series of temporal minima, and thus by a series of distinct observations. So this answer calls for some principled way to reify extended observations. Hume can't circumscribe the experience of a manner of disposition by unity of content (i.e., circumscribe individual experiences such that any change in input means a different experience), since it is precisely the single and direct observation of a change in content that is supposed, on this view, to give us the idea of a succession. So if this account is going to work, observations must be distinguished in some other way.

Suppose, however, that observation-events including direct awareness of temporally-extended periods can be defensibly circumscribed. One might suggest that the experience of a succession is limited by some brute fact about human abilities: just as there is a contingent natural limit, owing to limits on visual perception, to the region of space we can be aware of, there is a limit to what span of time we can be aware of..$^{14}$ And this determines the extent of the experience of a manner of temporal disposition. But this leaves the last, and perhaps fundamental objection to identifying an idea of succession with a succession of ideas. Hume's position appears to be that the consciousness of a succession somehow just $i$ s the mere occurrence of a series of states individually reflecting the parts of the succession. The reason why this suggestion might be viewed as a non-starter has to do with the Kantian critique of Hume on the unity of consciousness and the possibility of judgment. Hume denies mental substance, and does not seem to recognize any need for the presupposition of one in judgment. His denial implies the notion of 
ideas that represent just by their qualities, versus representing by virtue of how we as subjects of experience read the contents of our ideas. Kant points out that this would not explain the possibility of the bringing together of diverse representations in judgment. In particular, it is central to his position that the mere occurrence of a series of states that individually mirror the parts of a succession cannot give rise to the idea of a succession. The mere occurrence of a sequence of states bearing certain relations to each other doesn't tell us anything about how these states should be combined in judgment. For one thing, these states need to be, at a minimum, presumed to all be one's own states, and Hume notoriously can explain neither this phenomenon nor the content of the thought of a persisting self. Kant also argues convincingly that, since a succession of perceptions can be variously interpreted as resulting from the replacement of one item with another, or the result of changing perspectives on a static state of affairs as opposed to a process, concepts like substance and cause must be in play as a necessary condition of making any judgment one way or the other. (See Bardon, 2002.) Thus his conclusion that the mere occurrence of a series of awarenesses of parts of a succession cannot amount to a judgment regarding the occurrence of a succession.

\section{DURATION AND TEMPORAL DISPOSITION}

One possibility worth considering is that Hume thought these problems do not arise because of the timelessness, on his view, of "steadfast" perceptions. In his discussion of time in the Treatise, Hume claims that we only represent time by imagining a succession of changing objects or perceptions (Treatise, $1.2 .5 ; 65$ ). ${ }^{15}$ It is certain, he says, that we have no idea of time (i.e., duration) without any changeable existence: there is no impression from which it would be derived. Therefore the idea of duration only applies to, or is derived from, successions, and unchanging ("steadfast") perceptions are really durationless. He explains how we come to the mistaken conclusion that the notion of duration applies to something unchanging:

we may observe, that there is a continual succession of perceptions in our mind; so that the idea of time being ever present for us; when we consider a steadfast object at five-a-clock, and regard the same at six; we are apt to apply to it that idea in the same manner as if every moment were distingush'd by a different position, or an alteration of the object. (Treatise, 1.2.5; 65)

We tend to think of the unchanging perception or object in question as one that could have changed (but did not) in the time period marked off by the succession. But the passage of time really only properly applies in the case of change. This claim implies the apparently contradictory result that it is possible for a single, 
indivisible moment to coexist with a succession of moments. I shall call this the 'coexistence problem.' Don Baxter argues that it was Hume's view that our experience of time is composed of various successions of perceptions, which we then associate with each other temporally by virtue of perceived relations of contiguity, resemblance, and causation (Baxter, 2001). Moments, Baxter explains, for Hume are abstractions from members of successions, and some moments are abstractions from steadfast perceptions (Baxter, p. 135). Further, since only spatial minima are in space, no moment is in more than one place. There is no meaning, on Hume's view, to the notion of an objective time-order according to which all successions and their parts can be related to each other on a single timeline; rather, for Hume, "there are different successions of intervals in different places, with no subintervals in common." The passage of time is local, and any single, 'universal' timeline is a psychological construct. In this way, steadfast perceptions, only erroneously ascribed duration, can coexist with other perceptions undergoing duration. The coexistence problem only arises if "we assume that time is like a line and so if an interval coexists with a succession of intervals, then the latter intervals are subintervals of the former" (Baxter, p. 134).

If a unitary moment of perception can coexist with a succession of perceptions, then Hume might be thinking of our awareness of the manner of disposition of a succession of notes as a kind of unitary, timeless experience that coexists with that succession. Hume's description of a steadfast object is of an object or perception that does not change, and a perception of a succession is certainly not steadfast. Yet, as is clear in the flute comment, he did treat awarenesses of temporally complex manners of disposition as unitary experiences of a sort. The manner of disposition of a succession of perceptions, being determined by the pattern of changing perceptions itself, does not itself change with the changing perceptions. That suggests he could have embraced the notion that the experience of the manner of disposition of a succession is a kind of single, steadfast - and thus timeless - experience. This would make sense of the seemingly contradictory claims that the experience of the manner of disposition of successive perceptions (a) coexists with a series of perceptions (of the component parts) and (b) is also a unitary experience. Further, if such an experience counts as both unitary and timeless, then Hume need not allow that the experience of a successive manner of disposition is constructed from memory; nor would he need to acknowledge questions as to what point in the succession the idea is formed, or how an extended act of awareness can encompass an extended event as a whole, or how the elapsed portions of an act of awareness can have the same status vis-à-vis observation as the present portion.

There is one critical objection to the proposal that the experience of a manner of disposition is a kind of steadfast and timeless perception: this proposal would not allow for the answer Baxter gleans from Hume regarding the coexistence problem. Hume's answer, he claims, is that we register different successions (and thus 
different moments) as taking place in different locations, with no direct temporal correspondence between them. We construct an overall timeline from perceived relations between successions. But this solution to the coexistence problem would not work in the case of the coexistence of successive perceptions with durationless experiences of the manners of disposition of those same successive perceptions: the succession and its manner of disposition in such a case would not be represented as occurring at different places, and so the succession and its manner of disposition would not be associated by virtue of contiguity, causation, or any other psychological spur. The manner of disposition of the succession is not only local but essentially an aspect of the very same succession. There would be no way to understand the moments abstracted from the successive perceptions and the supposedly durationless moment abstracted from the whole succession except as coexisting in the same time-frame, which would result in the contradiction that defines the coexistence problem. ${ }^{16}$

A theory of time-awareness taking ideas and impressions to be copies of what they represent, including the manners of disposition of the component parts of what ideas of succession represent, thus seems to work either by circularly presupposing temporal concepts, by equivocating on the notion of the perceptual present, or by unworkably eliminating that notion altogether. Further, under an interpretation of Hume that answers these concerns by taking experiences of manners of disposition to be durationless, there is no obvious way to solve the coexistence problem that arises.

So for now it seems that no empiricist theory successfully accounts for temporal concepts. ${ }^{17}$ As long as we agree that temporal concepts are necessary to coherent experience of the world around us and our own thoughts, and that we cannot account for temporal concepts by reference to experience, then we need to take seriously the possibility of a priori elements in cognition. ${ }^{18}$

\section{REFERENCES}

Anderson, Robert (1976) 'The Location, Extension, Shape, and Size of Hume's Perceptions', in Donald Livingston and James King, ed., Hume: A Re-evaluation (New York: Fordham University Press).

Anderson, Robert (1980) 'In Defense of Section V: A Reply to Professor Yolton', Hume Studies 6.

Annand, M.R. (1930) 'An Examination of Hume's Theory of Relations', Monist 40.

Augustine (1961) Confessions, trans. by R.S. Pine-Coffin (Middlesex: Penguin Books).

Bardon, Adrian (2002) ‘Temporal Passage and Kant's Second Analogy', Ratio 15.

Baxter, Don (2001) 'Hume on Steadfast Objects and Time', Hume Studies 27.

Bayne, Timothy (2001) 'Co-consciousness: Review of Barry Dainton's Stream of Consciousness', Journal of Consciousness Studies 8.

Broad, C.D. (1938) An Examination of McTaggart's Philosophy, Vol. 2 (Cambridge: Cambridge University Press).

Dainton, Barry (2000) Stream of Consciousness (New York: Routledge). 
Falkenstein, Lorne (1990) ‘Was Kant a Nativist?” Journal of the History of Ideas 51.

Falkenstein, Lorne (1995) 'Hume and Reid on the Simplicity of the Soul', Hume Studies 21.

Falkenstein, Lorne (1997) 'Hume on Manners of Disposition and the Ideas of Space and Time', Archiv f. Gesch. D. Philosophie 79.

Falkenstein, Lorne (2002) 'Hume and Reid on Hardness', Hume Studies 28.

Falkenstein, Lorne (2004) 'Nativism and the Nature of Thought in Reid's Account of Our Knowledge of the External World', The Cambridge Companion to Reid Cambridge: Cambridge University Press.

Garrett, Don (1997) Cognition and Commitment in Hume's Philosophy Oxford: Oxford University Press.

Guyer, Paul (1987) Kant and the Claims of Knowledge Cambridge: Cambridge University Press.

Hume, David (1975) Treatise of Human Nature ed. by L.A. Selby-Bigge, 2nd Ed., rev. by P.H. Nidditch, Oxford: Clarendon Press.

Kant, Immanuel (1998) Critique of Pure Reason, ed. and trans. by Paul Guyer and Allen Wood (Cambridge: Cambridge University Press).

Kelly, Sean (2003) 'Husserl and Phenomenology', Blackwell Guide to Continental Philosophy, ed. by Robert Solomon and David Sherman (London: Blackwell).

Kelly, Sean (forthcoming) 'The Puzzle of Temporal Experience', Philosophy and Neuroscience Cambridge: Cambridge University Press.

Kelly, Sean (unpublished) 'Some Notes on Temporal Awareness."

Lacey, Hugh (1968) "Empiricism and Augustine's Problems About Time', Review of Metaphysics 22 .

Locke, John (1975) An Essay Concerning Human Understanding, ed. by Peter Nidditch (Oxford: Oxford University Press).

Mabbott, J.D. (1967) 'Our Direct Experience of Time', in Richard Gale, ed., The Philosophy of Time Garden City: Anchor Books.

Markosian, Ned (2004) ‘A Defense of Presentism', Oxford Studies in Metaphysics Vol. I, ed. by Dean Zimmerman, Oxford: Oxford University Press.

Mundle, C.K. (1966) 'Augustine's Pervasive Error Concerning Time', Philosophy 41.

Odegard, Douglas (1978) 'Phenomenal Time', Ratio 20.

Paton, H.J. (1929) 'Self-Identity', Mind 38.

Rosenberg, Alexander (1993) 'Hume and the Philosophy of Science', The Cambridge Companion to Hume, ed. by David Fate Norton, Cambridge: Cambridge University Press.

Russell, Bertrand (1927) An Outline of Philosophy (London: George Allen \& Unwin).

Smith, David and McIntyre, Ronald (1982) Husserl and Intentionality (Dordrecht: D. Reidel).

Frasca-Spada, Marina (1998) Space and the Self in Hume's Treatise (Cambridge: Cambridge University Press).

Tweyman, Stanley (1974) 'Hume on Separating the Inseparable', in William Todd, ed., Hume and the Enlightenment (Edinburgh University Press: Edinburgh).

Waxman, Wayne (1994) Hume's Theory of Consciousness (Cambridge: Cambridge University Press).

Yolton, John (1980) ‘Hume’s Ideas', Hume Studies 6. 
${ }^{1}$ Mundle's concerns clearly are equally applicable to the concept of duration.

${ }^{2}$ As Lorne Falkenstein points out, an empiricist who is not a realist about sensible qualities must say that our ideas of such qualities are occasioned by certain sorts of senseperception, rather than caused by perceptions of such qualities. See Falkenstein, 2004, p. 157.

${ }^{3}$ One can presently sense past events in that there are time-delays attributable to the finite speeds of light and sound; but this is not what Russell has in mind.

${ }^{4}$ Alexander Rosenberg argues that Hume's account is circular, in that the concept of time depends on the notion of a succession of impressions, which in turn refers to the notion of succession in time (Rosenberg, 1993, p. 83). Time, therefore, cannot be identified with a manner of disposition, and similarly for space. I think that this objection just gets at the primitiveness of spatial and temporal relations, be they relations between perceptual minima or between objects and events. I think that Hume would agree that we can only characterize the manners of disposition or appearance of minima spatially and temporally, and so this kind of "circularity" is inevitable. A "God's eye" characterization of how the world is independent of spatial and temporal relations is beyond us, since we could have no corresponding impression.

${ }^{5}$ For reasons discussed earlier with regard to Broad's presentedness quality, neither could the relative vivacity or clarity of memories, even if reliably correlated with age, be the source of the idea of time by virtue of inference: in order to associate vivacity with age, we would have to already possess a concept of age.

${ }^{6}$ Hume sometimes seems to use "disposition" specifically for arrangement in space (e.g., Treatise $1.2 .3 ; 35$ ), but he also refers to successiveness in time at least once as a species of disposition (Treatise $1.2 .3 ; 37$ ). Since his treatments of space and time were clearly intended to be parallel, I shall refer to arrangements of impressions or ideas in time as a "manner of disposition."

${ }^{7}$ Marina Frasca-Spada, like Falkenstein, sees the origin of the ideas of space and time for Hume in the manner of the appearance of spatial and temporal minima, but sees this phenomenon as an exception to the copy principle, rather than as consistent with it. See Frasca-Spada, 1998, pp. 59-65.

${ }^{8}$ As with other abstract ideas like cause, their origin in mere psychological propensities of mind did not stop Hume from making full use of them in his own theories. In the Treatise Hume identifies a number of abstract ideas (like cause, for example) that he argues do not have the origin or content we may have thought they did, but this makes him all the more concerned to explain their origin in experience (and in so doing better explain their content). The derivative status of space and time as mere abstract ideas does not distinguish them from any other general concepts for Hume. Wayne Waxman argues that, for Hume, abstract ideas are not ideas at all (Waxman, 1994, p. 100), but as he concedes (p. 101) this does not stop Hume from using abstract language all the time.

${ }^{9}$ The likeness principle has some curious consequences with regard to the physical properties of ideas. This principle implies that ideas may not only be extended in space and distended in time, but also loud, colored, hard, and smelly. John Yolton goes so far as to take Hume's comments implying the likeness principle to be satirical (Yolton, 1980). Falkenstein clearly has some sympathy for this doctrine: while he thinks there are problems with Hume's theory of perception, he thinks it is not clearly the case that Hume makes a category mistake in ascribing spatial extension and other physical properties to impressions and ideas. Falkenstein, 1997, pp. 191ff, and Falkenstein, 2002, pp. 38ff.

${ }^{10}$ Kant agrees with Hume that space and time have to do with the manner in which objects or representations are arranged, but for Kant the application of a priori concepts is needed in order to bring this arrangement to consciousness. (Cf. Falkenstein, 1990). He would argue, then, that an idea that brings together temporally-diverse elements presupposes an a priori synthesis under concepts. Hume's theory, on the above reading, avoids that 
requirement: if an experience of a succession can consist just in a copy of a succession of impressions, then no further synthesis is required.

11 Presentism has been attacked for not being able to account for singular propositions about non-present objects or past or future times (such as "Socrates was a philosopher," or "2008 will be a great year for the stock market"). It has also been accused of being incompatible with the Special Theory of Relativity, which allegedly rules out the possibility of absolute simultaneity. For a defense of presentism against these concerns, see Markosian, 2004.

12 Such questions all presuppose a spatially- and temporally-located perceiver, capable of compound perceptions. Hume, of course, famously denies our having knowledge or even a coherent idea of such a thing. I can give two answers to this point. First, this just relocates the problem of representing a succession as a succession to the problem of what constitutes a set of perceptions as a set belonging to one person rather than to several, and Hume does not have an answer to this. Second, our not having knowledge of a self doesn't stop us or Hume from presupposing a continuing self in other contexts any more than our not having knowledge of necessary connections stops us from speaking in terms of causation. For these reasons I think this kind of question is a fair one, even if on Hume's strict view we are just talking about bundles of perceptions.

13 Barry Dainton defends the notion of something like an extended present of perception (Dainton, 2000). His account, however, is strictly phenomenological. Furthermore, the topography of his "diachronic co-consciousness" may not be coherent: see Bayne, 2001, p. 85. I would reassert in any event my skepticism regarding any view that does not allow us to talk in principle about what we are experiencing at a moment.

14 As Falkenstein has suggested in correspondence. It is also his view that Thomas Reid maintained a position like this.

15 As discussed in Garrett, p. 55, and in Baxter, 2001. Baxter explains that Hume takes steadfast objects to include perceptions, and that he focuses on perceptions rather than objects in his discussion of time. I shall, therefore, put the following in terms of steadfast perceptions vs. successions of changing perceptions.

16 Further, as Baxter has pointed out in a comment on this paper, it seems that the likeness principle requires that a succession of different process-stages be represented by different perceptions.

17 Some readers may be wondering whether Husserl's famous analysis of the phenomenology of time-awareness might be employed in support of an empiricist account of time-awareness. But, like Kant, Husserl thinks that raw sense-data are subjected to conceptualization as a necessary condition of their becoming part of conscious experience. This is equally true for Husserl when it comes to generating the kind of presentation of the present, just-past, and the anticipated near-future that he discusses in his analysis of time-awareness. See Smith and McIntyre, 1982; cf. Kelly, 2003.

${ }^{18}$ I am grateful to Don Baxter, Marina Frasca-Spada, George Graham, and Ralph Kennedy for their comments on earlier versions of this paper. Conversations with Sean Kelly on related subjects were also helpful; Kelly's work on time-awareness has influenced mine in these pages. This paper was presented at the 2004 Atlantic Canada Seminar on Early Modern Philosophy, the 2005 APA Central Division meeting of the Philosophy of Time Society, and the 2006 Hume Society meeting; I benefited from the comments of a number of participants at those meetings. I am indebted to two anonymous Hume Studies referees for their commentary. Finally, Lorne Falkenstein's generous and extensive comments on two earlier drafts were invaluable and influenced many parts of this paper. 